Woith, H. (2015): Radon earthquake precursor: A short review. - European Physical Journal Special Topics, 224, 4, 611-627.

https://doi.org/10.1140/epjst/e2015-02395-9 


\title{
Radon earthquake precursor: a short review
}

\author{
Heiko Woith ${ }^{*}$
}

GFZ German Research Centre for Geosciences, Potsdam, Germany

\begin{abstract}
More than 100 publications reporting radon anomalies to precede earthquakes were evaluated. A clear apparent negative correlation between the number of reported anomalies and the published length of the timeseries is evident. 19\% of all timeseries are longer than 5 years, characterized by a precursor rate of less than one precursor per year, the extreme case being 1 anomaly in 18 years of monitoring. Contrary, precursor rates between 1 and more than 10 precursors per year stem from published timeseries shorter than 3 years. Nearly $50 \%$ of the timeseries contain exactly one radon anomaly, independent of the length of the observation interval. Generally, the number of anomalies is about 5 times higher at sites where radon is measured in soil air as compared to radon in groundwater. In conclusion: (i) significant radon anomalies exist, and (ii) seismo-tectonically induced radon anomalies probably exist. But, radon anomalies of non-tectonic origin also exist and may look strikingly similar to tectonic ones. Thus, presumably only a fraction of all reported radon precursors are real in the sense that they are physically related to the preparation process of an impending earthquake.
\end{abstract}

\section{Introduction}

Today, there is a big gap between the public perception and the scientist's view with respect to the feasibility of earthquake prediction. Searching the internet on 19 February 2015 for "earthquake precursor" gave 390,000 matches in google, 33,000 in google scholar, 3,250 in Scopus, and 1,873 in Web of Science (ISI). Adding the search term "radon", the respective numbers reduced to $25 \%, 14 \%, 8 \%$, and $12 \%$. One-third of the radon precursor entries in google refer to just one specific case: The L'Aquila $\left(M_{w}\right.$ 6.3) earthquake of 6 April 2009, which had been "predicted" by a technician called Giampaolo Giuliani based on radon measurements. Although his predictions were false, they generated a world-wide media-hype. Scientists and the deputy head of Italy's Civil Protection Department were put on trial for manslaughter for not communicating the earthquake hazard properly [1-4]. A comprehensive summary on the status of operational earthquake forecasting had been compiled upon request of the Italian government to access the scientific knowledge of earthquake predictability [5]. Stefan Wiemer summarized the communication dilemma during an OECD workshop [6] on Earthquake Science and its contribution to society held in 2006 as follows: "Although we like to call it a time-dependent hazard model, others call it earthquake forecasting —and for the public this is „earthquake prediction“' Following Max Wyss [7], an earthquake prediction needs the following parameters to be specified with errors less than or equal to those indicated: the location $\pm 1 / 2$ rupture length, the size $\pm 1 / 2$ rupture length or \pm 0.5 magnitude units, the time $\pm 20 \%$ recurrence time, and the probability of occurrence, e.g. the number of successes divided by the sum of successes and false alarms. To date, we cannot predict earthquakes if we follow the strict definition given above.

*e-mail: radon@gfz-potsdam.de 


\subsection{Short history of earthquake prediction}

An overview about the history of earthquake prediction research was given by Giovanni Martinelli [8]. In the early seventies of the last century earthquake prediction deemed to be feasible within the near future. Models had been developed [9-11], people had been evacuated before the Haicheng (M 7.3) earthquake of 4 February 1975 [12, 13], potential precursors had been identified [14], and research projects were launched in many countries aimed to predict earthquakes. In California the Parkfield project [15] started in 1981, and in 1985 an official earthquake prediction had been issued by the USGS mainly based on the recurrence interval of magnitude $6+$ events. A magnitude 6 event should have occurred with a 95\% probability before the end of 1993 [16, 17]. The anticipated event finally occurred in 2004 - no precursors had been observed [18-20]. Geller argued that earthquake prediction appears to be inherently impossible [21-23] due to non-linear processes highly sensitive to details of the state of the crust within a large volume which cannot be measured. Others disputed some of the underlying key assumptions providing a more differentiated view towards the possibilities of future predictions [24, 25].

Reviews on hydro-geochemical precursors were provided by [26-33]. Gas eruption phenomena belong to the oldest reported precursors to earthquakes. Gold \& Soter collected many historical observations dating back to the year 1663 [34]. Probably the first to mention radon anomalies associated with earthquakes was Shiratoi [35] in 1927. A threefold radon increase in deep ground water observed before the Tashkent (M 5.5) Earthquake of 26 April 1966 [36] stimulated the international research on hydro-geochemical precursors. Until 1980 at least 91 radon anomalies before 46 earthquakes have been reported from the former USSR, China, Japan, Iceland, and the USA [37]. An up-date with respect to radon precursors was given by [38-40].

\subsection{Precursor evaluation approach}

Given the large number of reported precursors, the question arises why there is no or only little progress after 40 years of research. Already in 1989, the International Association for Seismology and Physics of the Earth's Interior (IASPEI) issued a call to submit potential earthquake precursors to an evaluation panel for a critical review going beyond the classical peer review system. By 1991 just 20 cases had been nominated and reviewed [7]. By 1997 a total of 40 nominations had been reviewed [41]. Only five cases made it into a preliminary list of significant precursors; two out of these five were related to physico-chemical groundwater properties: Radon concentration and water temperature decrease before the 14 January 1978 Izu-Ohima-Kinkai (M 7) earthquake in Japan nominated by Hiroshi Wakita [33, 42], and groundwater rise before the 4 August 1985 Kettleman Hills (M 6.2) event in California proposed by Evelyn Roeloffs [43]. The good news is that two groundwater related phenomena made it into the list. The bad news is that only 5 cases made it at all. This does not compare to the number of published case studies. One of the necessities for a successful nomination was "to provide a long-term record of data so that the long-term signal and noise characteristics can be evaluated." Adopting the idea of the evaluation panel that the length of presented data is an important parameter, the focus of this review is exactly on the length of the timeseries provided by the authors. Of course, such a simplistic statistical approach will not permit - and is not intended to make - statements about the quality of single cases.

\section{Database and Methods}

The statistical part of this review on radon precursors is based on the evaluation of 105 publications (about 80\% ISI journals) reporting fluid-related anomalies to precede earthquakes. The dataset contains case studies where the authors have claimed to have documented a radon anomaly prior to an earthquake, i.e. a precursor [26, 36, 42-144]. In case, 
the same precursory anomaly has been reported several times, only the publication with the longest timeseries has been used for the evaluation. Only those studies were included, where a figure of the timeseries was presented. Papers about co- and postseismic responses, as well as rare cases of radon timeseries without seismo-tectonic anomalies [145-148] were excluded. 87 publications report precursory changes observed in fluid parameters which have been subdivided into three categories: radon (in air, soil gas, and groundwater), gas-geochemical parameters (He, $\mathrm{H}_{2}, \mathrm{CH}_{4}, \mathrm{~N}_{2}, \mathrm{Ar}, \mathrm{Pb}, \mathrm{Cl}, \mathrm{SO}_{4}$ ), and physical parameters (water level, water temperature). The selection process was arbitrary and by no means complete - hence short review. The dataset is further biased due to the fact that the majority of publications was written in English; thus a significant number of Russian, Chinese and Japanese publications is likely missing. On purpose, the dataset is biased in the sense that the focus was on radon precursors.

Only those publications were selected where the authors themselves claimed that they found a precursor to an earthquake. No filters in terms of data quality or presumed reliability have been applied. If tables were given, the number of anomalies were extracted from the tables; in some cases the statements were taken from the text; in a few cases the number of earthquake related anomalies were extracted from figures. The same applies to the length of the published time series. Note, that the timeseries from a specific monitoring site might be much longer than the presented selection. If the total observation period covers e.g. 9 years, but only 3 years of data are presented in graphical form, then the "length of the published timeseries" is 3 years. Actually, this procedure is fundamental to understand the presented results.

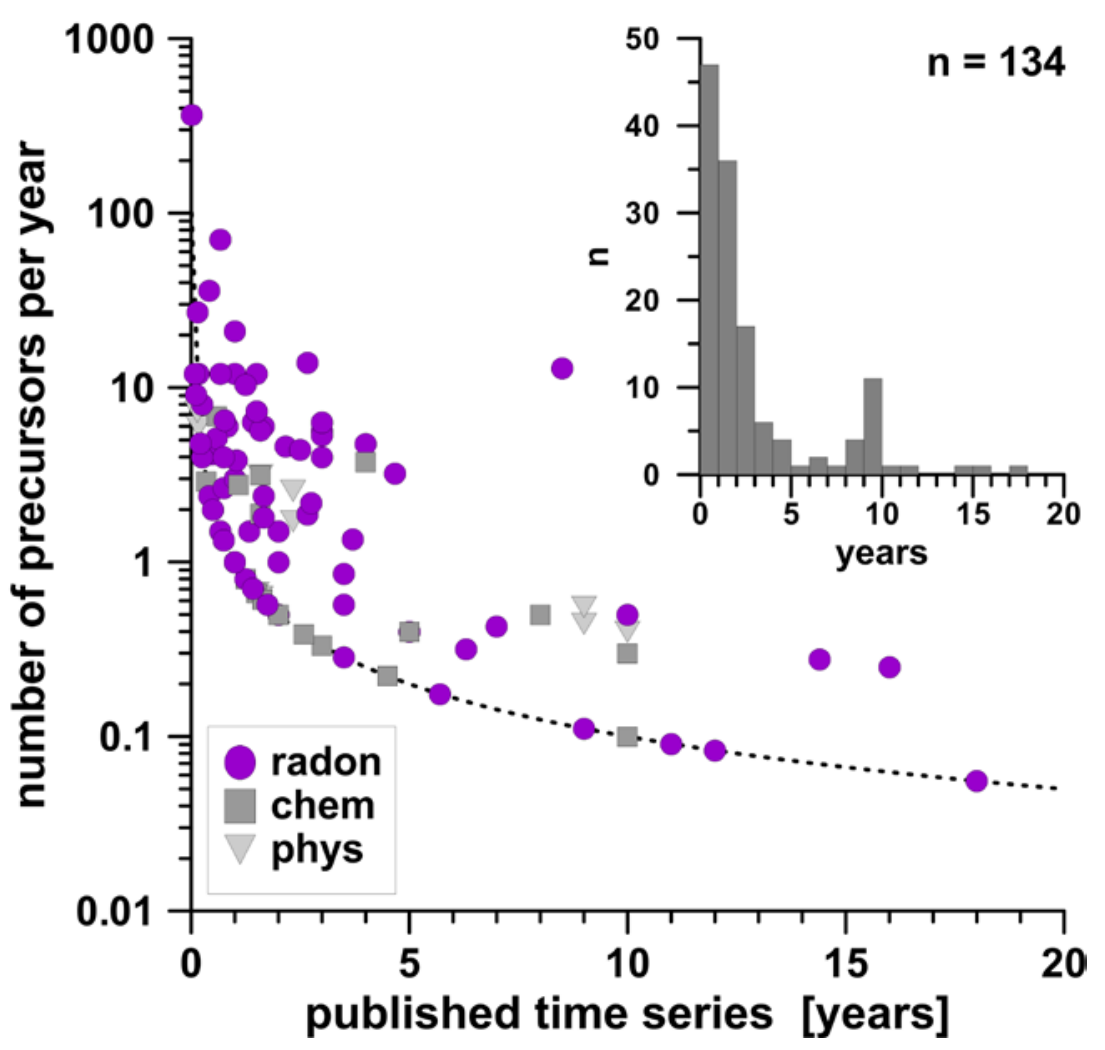

Fig. 1 Number of precursors per year vs. length of the published time series for three categories: radon - radon in air, soil, and groundwater; chem - gas-geochemical parameters (like $\mathrm{CO}_{2}, \mathrm{H}_{2}$ ) in soil and groundwater; phys - physical groundwater parameters (water level, water temperature). The dotted line indicates a 1/x distribution ( $x=$ time). 


\section{Results and Discussion}

\subsection{Statistics of radon earthquake precursors}

The dataset contains 147 timeseries from 87 publications which appeared between 1967 and 2014. At 13 sites, no anomalies were detected. Thus, 134 cases report radon, gasgeochemical, and physical groundwater anomalies prior to earthquakes. The majority (63\%) of precursors are reported from India, Japan, Iceland, Russia, USA, China, and Taiwan. All other countries (19) contribute with 1 to 5 cases to the list. A wide range of magnitudes (1.69.1) and distances between earthquakes and the monitoring site $(1.5-2,275 \mathrm{~km})$ are covered. An in-depth discussion of these and further statistical properties of the anomalies is beyond the scope of this paper; the reader is referred to the review provided by Cicerone et al. [39]. Out of 134 cases, 93 refer to radon, 27 to gas-geochemical parameters (most of them referring to $\mathrm{He}, \mathrm{H}_{2}$, and ion content of groundwater, specifically $\mathrm{Cl}^{-}$), and 14 to physical groundwater parameters water level and water temperature.

About two-third of the observations relate to changes in groundwater, one-third to anomalies in soil gas. The length of the published timeseries varies between 4 days and 18 years. One third (36\%) has a length of 1 year or less; $75 \%$ are shorter than 3 years while $19 \%$ are longer than 5 years (see histogram in Fig. 1). Nearly 50\% of the timeseries contain just one anomaly independent of the length of the timeseries - see symbols plotting on the dotted line indicating a $1 / x$ distribution. Extreme values are 1 anomaly in 18 years [26], and 110 anomalies observed at one monitoring site during 8.5 years [122].

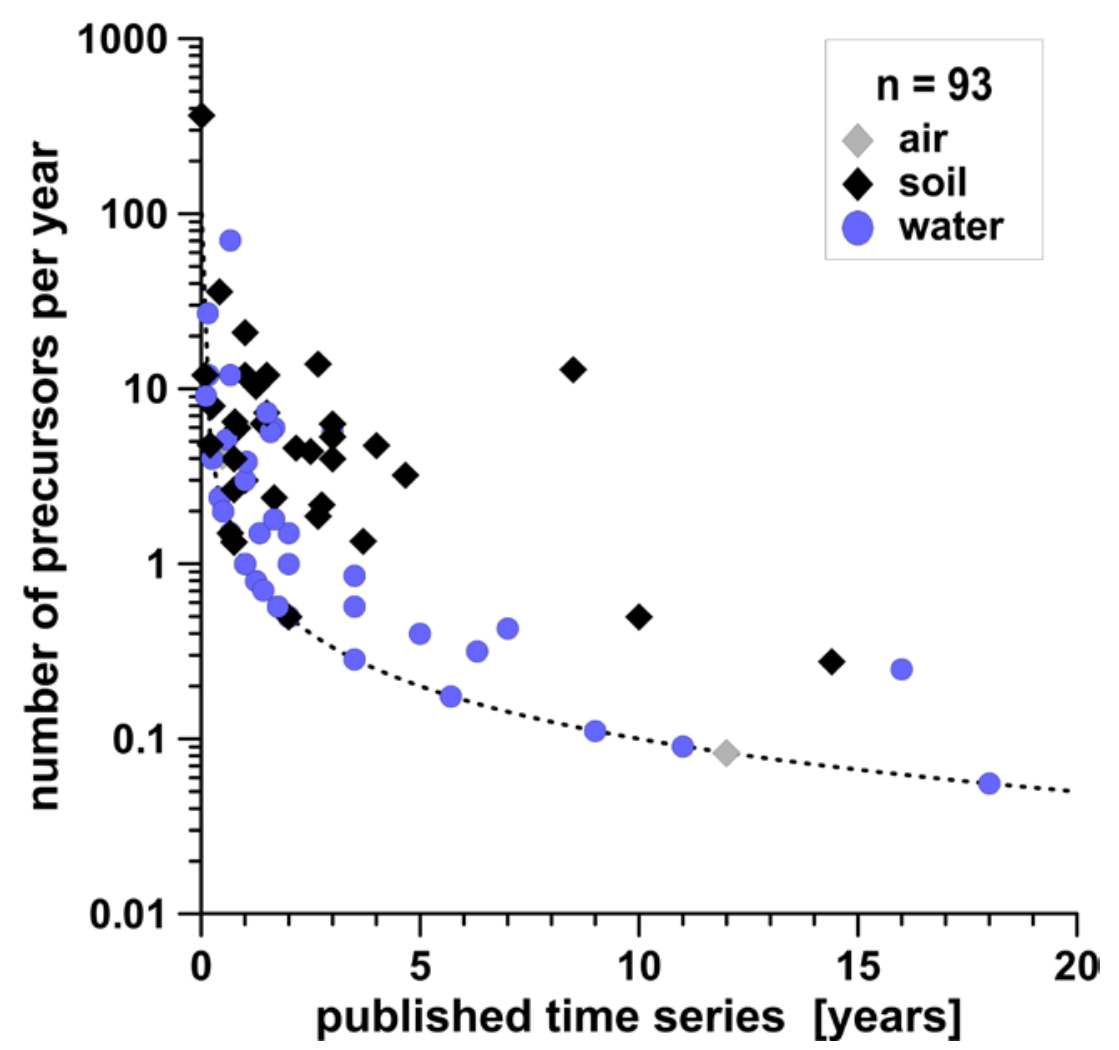

Fig. 2 Number of radon precursors per year vs. length of the published time series for categories air, soil, and groundwater.

Out of 93 case studies reporting radon precursors, 40 are related to radon measurements in soil gas while 51 cases refer to radon (dissolved) in groundwater. In one case radon was monitored indoor, in another case radon was measured in the atmosphere $5 \mathrm{~m}$ above the 
ground. The median number of radon precursors measured in soil gas is about 5 times higher compared to the number of radon anomalies observed in groundwater (Fig. 2). This statistically obtained finding is corroborated by other observations. Soil radon anomalies were observed around the Sea of Marmara, while no anomalies were found in the physico-chemical properties of thermal/mineral waters in the same region and time period [74]. Hartmann \& Levy [31] tried to assess the data quality of proposed precursors and came to a similar conclusion: only $22 \%$ of 132 radon signals could be confirmed as reliable according to their rules, whereas 95\% of 21 hydrochemical signals (changes in groundwater ion content like $\mathrm{Cl}^{-}$) indicating groundwater mixing were confirmed as potential precursors.

\subsection{Anomaly detection}

By far the most popular attempt to relate radon anomalies with earthquakes was - and still is a 1:1 approach, i.e. one radon anomaly is related to one earthquake. In most of the investigated cases the anomalies are spike-like with a good signal-to-noise ratio. But sometimes it is not obvious why some spikes are identified as anomalies, while similar signals in the same timeseries are not. Whereas the anomaly definition is more or less straightforward (usually 2 standard deviations above the average are regarded as anomalous), the selection of the "corresponding" earthquake is not. In fact, this is the most critical, sometimes arbitrary procedure. Examples of selection criteria: (i) no criteria are given at all, (ii) only one specific event is selected (nearby and/or large), (iii) rarely, attempts are made to calculate the "strain impact" of an event taking into account the magnitude and distance from the monitoring site [141] applying an empirical formula provided by Dobrovolski [149]. Although a radon anomaly might be significant from a statistical point of view, no information is available about the physical origin of the anomaly from the radon value alone. Modern methods for detecting radon anomalies were discussed by [150], like artificial neural networks to learn about the dependency of radon on environmental parameters like air and soil temperature, barometric pressure, and precipitation.

\subsection{Physical mechanisms}

Few authors provide a model or a clear explanation for the origin of radon anomalies. Generally, "stress changes" are claimed to be responsible for the opening or closing of cracks, pore pressure changes, or mixing of different groundwater components. Excellent evaluations of potential mechanisms behind geochemical precursors were carried out by Roeloffs [29] and Thomas [28]. The latter featured the "increased reactive surface area" (IRSA) model and the "aquifer breaching/fluid mixing" (AB/FM) model. From laboratory analysis it is known that radon emanation from rocks increases with increasing stress [151154]. Radon emanation from granitic rocks increased up to $170 \%$ at the macroscopic failure of the sample [154]. One problem arises with the IRSA model since micro-cracking should be expected only in a small volume around the future hypocenter and radon changes at depth will remain un-noticed at the Earth's surface. Exceptional conditions might have enabled the detection of the famous radon anomaly prior to the 1966 Tashkent earthquake. According to Mavashev [155], the observation well had a depth of $1,900 \mathrm{~m}$ located only $1.5 \mathrm{~km}$ from the epicenter ("pleistoseistal region"); the earthquake rupture started at a depth of $8 \mathrm{~km}$ and stopped at 2-3 km beneath the earth surface, i.e. close to the bottom of the monitoring well.

\subsubsection{Mixing}

Some ground water anomalies are apparently caused by mixing of different fluids, which are normally restricted to separated aquifers [144, 156, 157]. The changes were attributed to fracture formation within a separating aquiclude. Again, the physical mechanisms remain unexplained to date since considerable stress changes are needed to break up a hydrological barrier. Moreover, this model is useful to explain permanent changes, e.g. different stable 
isotope ratios before and after an event [158], but fails to explain repeatedly occurring anomalies unless post-seismic healing processes are assumed. This led to a modification of the $\mathrm{AB} / \mathrm{FM}$ model introducing changes in the hydraulic heads within different aquifers as the driving force for changes in the mixing ratio present in a ground water fed by two or more aquifers [29, 159]. A good example illustrating mixing of fluid end-members and temporal variations induced by rain and seismicity was given by Toutain et al. [160]. Gas-geochemical parameters are well suited to detect changes of mixing ratios between different end-members. Typically, thermal waters are a mixture of deep, hot fluids and cold, shallow groundwaters called end-members in a mixing scenario. Even tiny pressure changes in the crust may result in measurable changes of the fluid composition. In case of the Adana ( $\left.\mathrm{M}_{\mathrm{w}} 6.2\right)$ earthquake of 27 June 1998 the contribution of the deep fluid end-member co-seismically increased from $0.3 \%$ to $0.5 \%$ [161]. This tiny change was easily detectable in the groundwater chemistry, e.g. the $\mathrm{Cl}^{-}$concentration doubled from 1.5 to $3 \mathrm{mmol} / \mathrm{l}$ after the event and returned to the preevent level within three months.

\subsubsection{Radon carrier}

Finally, a radon specific mechanism has to be considered. Due to the short half-life of ${ }^{222} \mathrm{Rn}$ (3.82 days) its mobility in the ground by diffusion is limited to a few meters. Radon needs a carrier fluid, either in gaseous or in liquid form. This could be groundwater or gases like $\mathrm{CO}_{2}$, $\mathrm{CH}_{4}$, or $\mathrm{N}_{2}$ in a wide range of geological settings. Lab experiments with various carrier gases suggest that $\mathrm{CO}_{2}$ might be the most effective one in terms of radon transport [162]. Carrier velocities depend on pressure gradients and fracture widths and especially in presence of gas bubbles a very fast fluid ascent is possible [163] - theoretically in the range of 1-1,000 $\mathrm{m}$ /day for fissures in the sub-mm range. Given the importance of carrier fluids, it is surprising that systematic studies of radon and its carrier are still rare [70,164]. Especially a combination with isotope studies $\left({ }^{3} \mathrm{He} /{ }^{4} \mathrm{He} ; \delta^{13} \mathrm{C}\right)$ to identify the origin of the carrier gas would be helpful to identify promising radon monitoring sites. Based on an evaluation of gas ascent velocities in the context of oil exploration surveys [165] concluded "The effect of tectonic stress on fracture apertures could explain some of the temporal variability (lack of reproducability) of geochemical anomalies, because flux is extremely sensitive to fracture aperture." Thus, under favorable conditions radon may be used as a proxy for geodynamic processes.

\subsection{Meteorologically driven anomalies and man-made disturbancies}

Some authors right-out neglect any non-tectonic drivers to influence "their" radon timeseries. Others admit that there is a - sometimes significant - contribution of meterological parameters to the radon signal. e.g. [166] estimated the non-tectonic part of the radon signal to be of the order of $60 \%$. Few try to "predict" and correct for the non-tectonic part of the temporal radon variability using models taking into account potential external drivers like barometric pressure, air and soil temperature, and rainfall [167]. But there is another important issue related to the shape of identified anomalies itself: seismo-tectonically and meteorologically induced radon anomalies may look strikingly similar. In the following I will give two examples from my own radon monitoring experience.

\subsubsection{Rain induced mixing}

Within the frame of the "Turkish-German Joint Project on Earthquake Research" [168], I did my $\mathrm{PhD}$ on spatial and temporal variations of radon in ground air and ground water within the Mudurnu Valley, NW-Turkey [169]. In 1989 we started continuous monitoring of radon at a natural hot spring in Kuzuluk $\left(30.657^{\circ} \mathrm{E}, 40.629^{\circ} \mathrm{N}\right)$ in NW Turkey. Water temperature, specific electrical conductivity, $\mathrm{pH}$, and radon were recorded at hourly intervals. A unique, peak-like anomaly occurred on 18 October 1989 with 4 parameters showing significant deviations from the average values: water temperature dropped about $10^{\circ} \mathrm{C}$, specific electrical conductivity increased from $3.6 \mathrm{mS} / \mathrm{cm}$ to $4.9 \mathrm{mS} / \mathrm{cm}$, $\mathrm{pH}$ rose from 6.4 to nearly 6.6 and the 
radon content increased from $320 \mathrm{cpm}$ to $500 \mathrm{cpm}$ (Fig. 3, the monitoring station was located inside the cluster of thermal springs in the NE of the area). The whole anomaly lasted only one day, thereafter all parameters returned to their previous values.

The "event" concentrations observed during 18 October 1989 could be modelled by mixing about $60 \%$ of thermal water with about $40 \%$ of cold mineral water (see table in Fig. 3). From isotope investigations [170] it was known that mixtures of thermal and mineral waters occur spatially within the Kuzuluk geothermal field (as indicated by water temperature and conductivity in the map of Fig. 3). The story was nearly perfect - except that there was no earthquake. Instead, there where severe rainfalls in the area in the night before the anomaly, further details are given in [161]. The non-tectonic signal looks very much like a tectonic anomaly, because the underlying physical mechanism is the same - in this case a changed mixing ratio between different fluid end-members driven by pressure changes in one endmember.

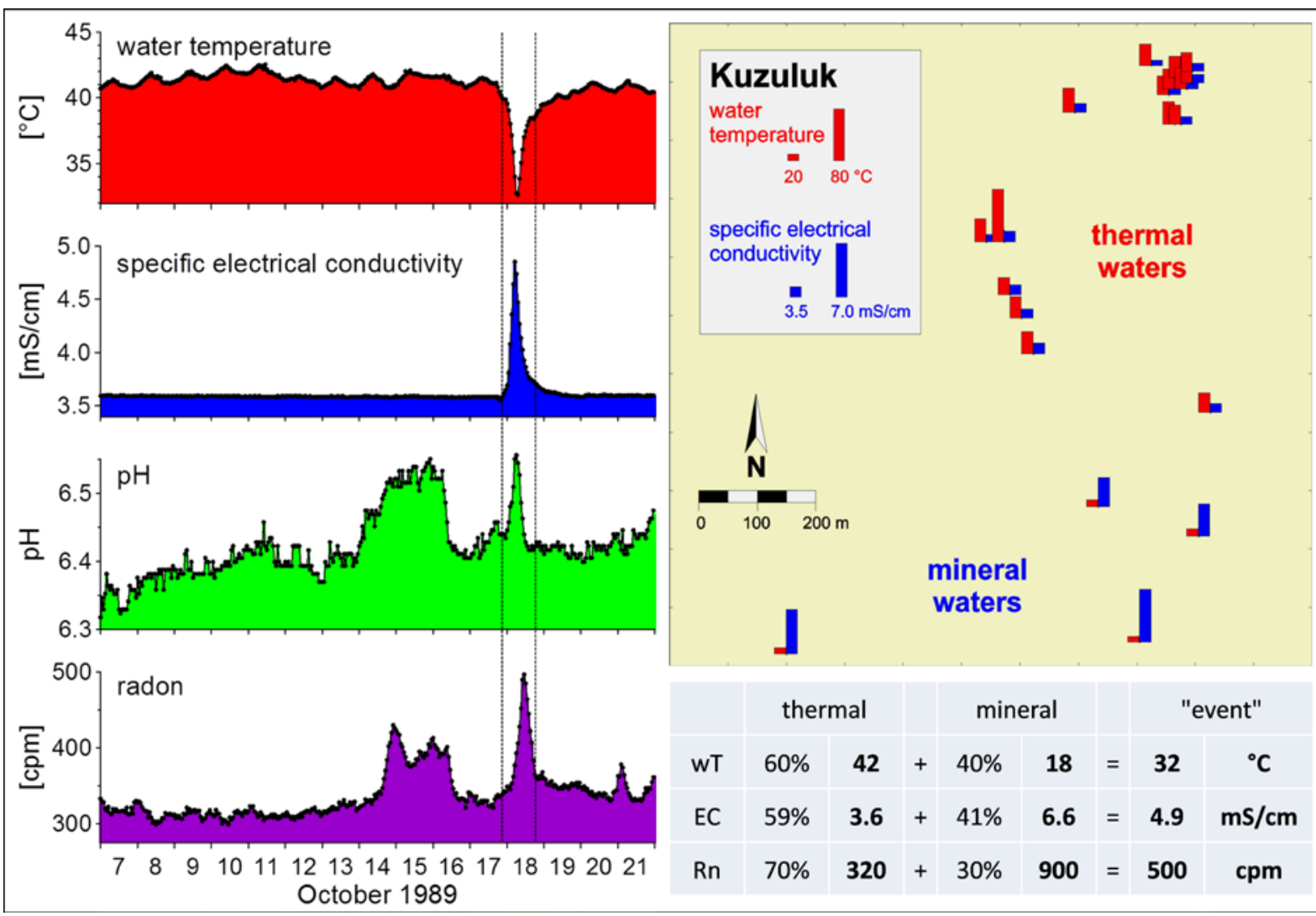

Fig. 3 (left) Anomaly of physico-chemical parameters at Kuzuluk hot spring, NW Turkey [169], (right) map showing location and properties of thermal and mineral springs in the Kuzuluk geothermal area; values given in the table indicate the mixing ratios between the end-members "thermal" and "mineral" to obtain the "event" composition for water temperature (wT), specific electrical conductivity (EC), and radon (Rn).

\subsubsection{Pore-pressure disturbance}

In the following I present another example to illustrate the similarity of seismo-tectonically and externally induced radon signals. The radon spectrum shown in Fig. 4 top left clearly indicates the presence of Earth tides $\left(\mathrm{M}_{2}\right)$ in the radon concentration of an artesian, i.e. free flowing mineral water well in Kajaran, southern Armenia. After the passage of seismic waves originating from the Izmit (M 7.4) earthquake of 17 August 1999 at a distance of 1,400 km with respect to the monitoring site, the Earth tides disappeared from the signal and the noise level in general was significantly reduced. We modelled the Kajaran system and could demonstrate that seismic waves dynamically induce pore pressure disturbances in the local 
aquifer lasting for several months before the pre-event conditions were established again [171, 172].

The right panel of Fig. 4 shows two-months Fourier spectra of radon concentration in a natural hot spring in Afyon, Turkey. Under normal conditions, clear daily and half-daily variations are visible (top right). These periodic variations disappeared during a massive fluid production test during November/December 1995. From nearby wells in the vicinity (some $100 \mathrm{~m}$ ) of the natural spring, large amounts of hot water were extracted from the reservoir during the test. Again, in both cases the physics is the same. In this example it is a disturbance of the pore pressure regime within the aquifer. A similar observation had been made by [173]: typically ever-present diurnal radon variations disappeared for nearly one week after an earthquake.
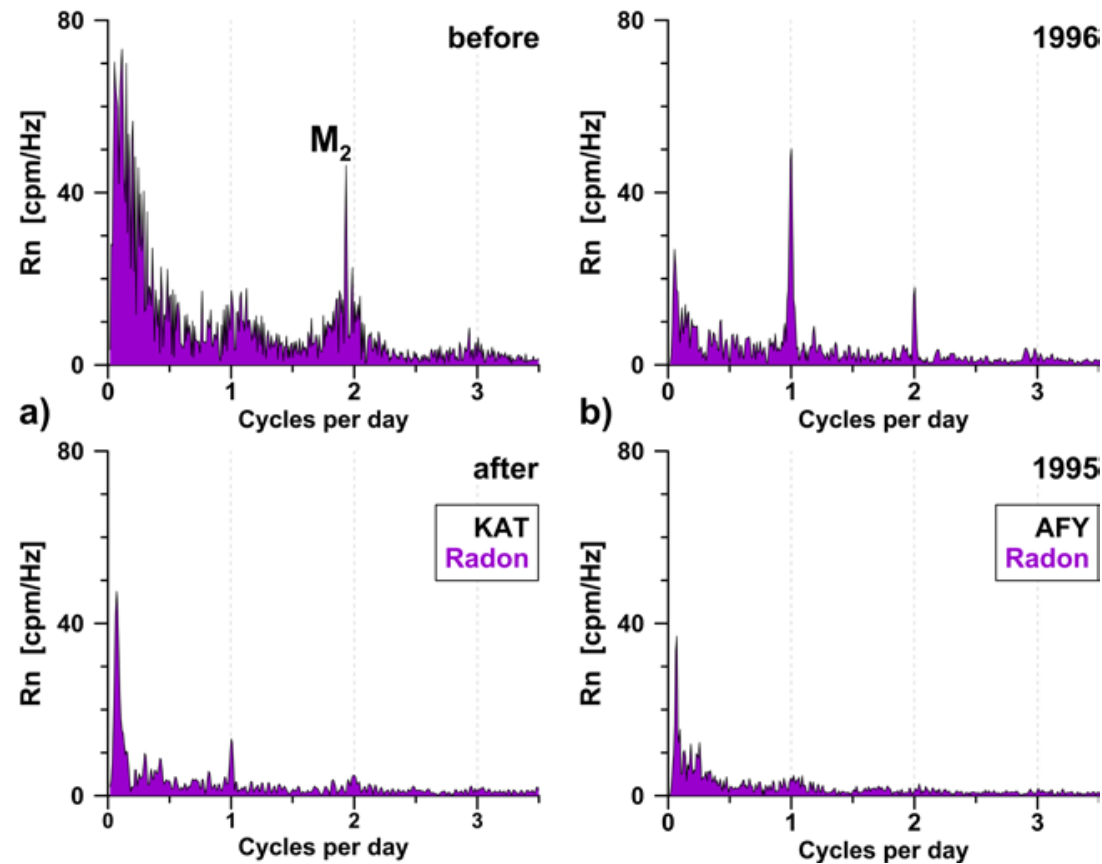

Fig. 4 Fourier spectra of radon from groundwater timeseries (a) mineral water well KAT in Kajaran, Armenia three months before and after the 1999 Izmit earthquake; (b) radon spectra from a natural thermal spring in Afyon, Turkey for two months in 1996 and 1995.

\section{Outlook}

A more rigorous procedure is desirable to evaluate potential earthquake precursors, e.g. by following the guidelines for the nomination of precursors (see box 3 in [7]) - highly recommended for both, authors as well as reviewers. Summarizing ideas and proposals of many researchers, I am trying to give some practical recommendations to improve the research aimed to identify radon precursors.

\subsection{Site selection}

In a pre-site survey, both radon and its potential carrier fluids should be investigated and mapped [164]. Isotope studies $\left({ }^{3} \mathrm{He} /{ }^{4} \mathrm{He} ; \delta^{13} \mathrm{C}\right)$ are useful to identify the origin of carrier fluids, specifically to quantify mantle contributions [174]. Once a monitoring station has been installed, the data should be critically evaluated for external influences like air pressure [175]. Indicators for meteorological influences are daily fluctuations, strong seasonal variations, or response to rainfall. Timeseries should be analysed for Earth tides, because (i) they indicate 
that a site is sensitive to strains of the order of $10^{-8}$, and (ii) temporal variations of the tidal admittance may be used as a proxy for permeability changes in the crust $[176,177]$.

The seismo-tectonic framework of the target area is worth to be considered for site selection. Emphasis should be on geometric singularities like intersecting faults, bending fault segments, oversteps, jogs, pull-apart basins etc., because fluid flow in the crust might be enhanced or reduced depending on the tectonic environment (cf. Fig. 5 in [178]). The complex interplay between crustal stress, faulting and fluid flow was discussed by Sibson [178-180]. Sibson's fault-valve hypothesis predicts fluid pressure cycles approaching near-lithosstatic prefailure values which "may give rise to detectable precursors to the nucleation of large ruptures...". Finally, seismic gaps are promising targets to observe crustal transients.

\subsection{Monitoring strategy}

Ideally, a multi-parameter, multi-site, and multi-level long-term monitoring approach should be aimed at. The idea is best illustrated by the new groundwater-strainmeter network which has been set-up recently in Japan [181]. Fourteen observatories have been established in the focal zones of the Nankai, Tonakai, and Tokai earthquakes; at each site wells have been drilled to depths of $30 \mathrm{~m}, 200 \mathrm{~m}$, and $600 \mathrm{~m}$ equipped with seismometers, groundwater level and temperature sensors. At some wells borehole strainmeters, tiltmeters, and GPS are installed additionally. The idea is to detect possible preseismic crustal deformation linked to preslip [182], a mechanism already proposed by [43] as one cause for precursory water level changes.

A well-designed field experiment to study natural systems under controlled conditions has been set-up in the French Alps [146]. In a tunnel close to artificial lakes with seasonal water level variations of more than $50 \mathrm{~m}$, radon bursts were observed repeatedly which could be related to rock deformation.

\subsection{Data description and analysis}

Improvement is needed in the proper documentation of the observations, e.g. by following the recommendations proposed by Roeloffs [29] and Kümpel [183]; an excerpt is shown in table 1. Data and metadata should be archived in a way that will allow sustainable access for interested researchers, either as electronic supplements to publications or as stand-alone data publications e.g. in archives.

A clear mathematical definition of anomalous values should be given. The potential of timeseries analysis should be exploited more rigorously. The computer program BAYTAP-G has been developed to separate an observed signal like groundwater level into several components: response to tides, barometric pressure, and rainfall, a noise component and the residual water level [184]. Wavelet-based scale-by-scale decomposition of timeseries might be a useful option to detect hidden patterns in monitoring data [145]. Regression trees offer a new way to distinguish seismo-tectonic anomalies from those caused by meteorological parameters [142].

The rules for the association of anomalies to subsequent earthquakes must be precisely stated. If strain changes are thought to be the mechanism for a precursory anomaly, then the strain impact at the monitoring site should be quantified. In cases where the focal mechanism of the earthquake is known, co-seismic static strain changes at the monitoring sites can be calculated using Okada's dislocation theory [185]. In case only the magnitude is known, Dobrovolsky's empirical formula [149] to estimate the strain impact at the monitoring site is probably a good estimator. This exercise should be performed for all earthquakes, because a small magnitude event next to the monitoring station might have the same strain impact as a large event at greater distance. 
Table 1 Checklist for documentation of monitoring sites and observations; modified and extended excerpt from $[29,183]$.

\begin{tabular}{ll}
\hline Monitoring site & site name, a unique site identifier (ID) is recommended \\
& geographic coordinates (map datum) \& elevation \\
& tectonic regime, distance to fault, geology, lithology, aquifer \\
& topography, vegetation, land-use \\
\hline Well & depth, diameter, casing (material, depth of screen sections) \\
& year of installation, purpose of the well \\
\hline Hydrogeology & mean water level or flowrate (artesian) \\
& degree of confinement, amplitude of seasonal variations \\
& water temperature \& composition (chemistry, isotopes, \\
& potioactivity), gas content (bubbles?), age and origin of fluids \\
& response to earth tides, barometric pressure, rain \\
& co-seismic response to earthquakes \\
\hline Environmental & meteorological data (rain, barometric pressure, air temperature, \\
parameters & pumped wells in the vicinity, water level in rivers/lakes \\
\hline Technicals & measurement technique \\
sensors: type, accuracy and resolution \\
datalogger/digitizer: type, sampling interval, clock accuracy/drift \\
\hline timeseries: longest available record should be shown; zoom into \\
anomaly showing raw data, meteorological data (if available) \\
earthquakes: latitude, longitude, magnitude, depth, focal \\
mechanism, azimuth and distance to monitoring site \\
description of sites which did not show anomalies \\
\hline
\end{tabular}

\subsection{Modelling}

An exceptionally interesting modelling approach had been elaborated by [160] to explain temporal variations of the groundwater chemistry at a mineral spring in the French Pyrénées. In a first step, they modelled the influence of rain on the mixing ratio of shallow and deep groundwaters. In a second step, the mixing model could be further improved by taking into account the influence of background micro-seismicity. A similar logic is behind the analysis of the evolution of the groundwater chemistry before the 1995 Kobe earthquake [186]. The authors claimed, that - at least partly - hydrochemical variations before this event could be related to seismo-tectonic activity.

Case studies are important, and the technical issues raised above have to be taken into account, but real progress only comes when we start to understand the physics behind precursors. Since real precursors are rare, a pragmatic intermediate approach is to study much more common - crustal transients as already proposed by Pascal Bernard [187]. Experiments from lab [188-190] to field scale, including laboratories at depth like KTB [191] and SAFOD [192, 193], will improve our understanding of mechanisms involved in the generation of transients and hence potentially precursory signals.

\section{Conclusion}

In conclusion: (i) significant radon anomalies exist, (ii) seismo-tectonically induced radon anomalies probably exist, and (iii) radon anomalies of non-tectonic origin exist and may look 
strikingly similar to tectonic ones. Thus, presumably only a fraction of all reported radon precursors are real in the sense that they are physically related to the preparation process of an impending earthquake. Radon is a powerful tracer for fluid movements and pressure transients in the crust, but we have to learn to distinguish external (meteorological, man-made) signals from seismo-tectonic ones.

\section{Acknowledgements}

I thank Susana Barbosa, both for the editorial handling as well as pushing me to publish this piece of work. Many thanks to my colleagues Birger-G. Lühr and Torsten Dahm for proposals and discussions. I am grateful for comments and suggestions made by an anonymous reviewer. Special thanks go to Max Wyss for concise and constructive reviewer comments, and for dragging me into the precursor business by forcing me to take the role of devil's advocate at a precursor session held at IUGG in Boulder/Colorado back in 1995. During the whole day pros and cons of earthquake precursors were discussed. During that time I was a young PhD student trying to predict the upcoming 1999 Izmit earthquake in Turkey with radon.

\section{References}

1. E. Cartlidge, Science. 338, 184-188 (2012)

2. S.S. Hall, Nature. 477, 264-269 (2011)

3. E. Boschi, Science. 341, 1451-1451 (2013)

4. E. Cartlidge, Science. 346, 794-794 (2014)

5. T.H. Jordan, et al., Ann. Geophys. 54, 315-391 (2011)

6. H. Woith, GAiA Ökologische Perspektiven für Wissenschaft und Gesellschaft. 15, 228-230 (2006)

7. M. Wyss, Evaluation of proposed earthquake precursors. (American Geophysical Union Washington D.C., 1991)

8. G. Martinelli, Seismol. Res. Lett. 71, 583-588 (2000)

9. $\quad$ Y.P. Aggarwal, et al., Nature. 241, 101-104 (1973)

10. C.H. Scholz, Sykes L.R., and Aggarwal Y.P., Science. 181, 803-810. (1973)

11. A. Nur, Bull. Seismol. Soc. Am. 62, 1217-1222. (1972)

12. K. Wang, et al., Bull. Seismol. Soc. Am. 96, 757-795 (2006)

13. M. Wyss and Wu Z., Seismol. Res. Lett. 85, 126-129 (2014)

14. T. Rikitake, Bull. Seismol. Soc. Am. 65, 1133-1162 (1975)

15. W.H. Bakun and Lindh A.G., Science. 229, 619-624 (1985)

16. A.J. Michael and Langbein J., Eos. 145-155. (1993)

17. $\quad$ E. Roeloffs and Langbein J., Rev. Geophys. 32, 315-336. (1994)

18. J. Langbein, et al., Seismol. Res. Lett. 76, 10-26 (2005)

19. W.H. Bakun, et al., Nature. 437, 969-974 (2005)

20. D.D. Jackson and Kagan Y.Y., Bull. Seismol. Soc. Am. 96, S397-S409 (2006)

21. R.J. Geller, Nature. 352, 275-276 (1991)

22. R.J. Geller, et al., Science. 275, 1616-1617 (1997)

23. R.J. Geller, Geophys. J. Int. 131, 425-450 (1997)

24. L.R. Sykes, Shaw B.E., and Scholz C.H., Pure Appl. Geophys. 155, 207-232 (1999)

25. M. Wyss, Tectonophysics. 338, 217-223 (2001)

26. H. Wakita, Proc. Nat. Acad. Sci. U.S.A. 93, 3781-3786 (1996)

27. J.P. Toutain and Baubron J.C., Tectonophysics. 304, 1-27 (1999)

28. D. Thomas, Pure Appl. Geophys. 126, 241-266 (1988)

29. E.A. Roeloffs, Pure Appl. Geophys. 126, 177-209 (1988)

30.

31.

32.

33.

34.

35.

36.

37.

38.

39.

40.

41.

C.Y. King, Zhang W., and Zhang Z.C., Pure Appl. Geophys. 163, 633-645 (2006)

J. Hartmann and Levy J.K., Nat. Hazards. 34, 279-304 (2005)

V.L. Barsukov, Varshal G.M., and Zamokina N.S., Pure Appl. Geophys. 122, 143-156. (1984)

H. Wakita, Nakamura Y., and Sano Y., Pure Appl. Geophys. 126, 267-278 (1988)

T. Gold and Soter S., Pure Appl. Geophys. 122, 492-530 (1984)

K. Shiratoi, Science reports of the Tohoku Imperial University. ser. III, 614-621 (1927)

V.I. Ulomov and Mavashev B.Z., Dokl. Earth Sci. 176, 9-11 (1967)

E. Hauksson, J. Geophys. Res. 86, 9397-9410. (1981)

D. Ghosh, Deb A., and Sengupta R., J. Appl. Geophys. 69, 67-81 (2009)

R.D. Cicerone, Ebel J.E., and Britton J., Tectonophysics. 476, 371-396 (2009)

H. Friedmann, Radiation Protection Dosimetry. 149, 177-184 (2012)

M. Wyss, Pure Appl. Geophys. 149, 3-16 (1997)

42. H. Wakita, Nakamura Y., and Sano Y., in Evaluation of proposed earthquake precursors, edited by M. Wyss. (American Geophysical Union, Washington D.C., 1991), pp. 15-20 
43. $\quad$ E. Roeloffs and Quilty E., Pure Appl. Geophys. 149, 21-60 (1997)

44. L. Allegri, et al., Geophys. Res. Lett. 10, 269-272 (1983)

45. G. Asteriadis and Livieratos E., Tectonophysics. 170, 1-2 (1989)

46. $\quad$ P.F. Biagi, et al., Pure Appl. Geophys. 157, 1359-1377 (2000)

47. $\quad$ P.F. Biagi, et al., J. Seismol. 5, 487-497 (2001)

48. $\quad$ S. Borchiellini, Bernat M., and Campredon R., Earth Planet. Sci. Lett. 107, 217-229 (1991)

49. K. Bräuer, et al., J. Geophys. Res. 112, B04307 (2007)

50. G. Buntebarth, et al., Cahier du Centre European de Geodynamique et de Seismologie, Luxembourg. 14, 65-79 (1997)

51. G. Buntebarth, et al., Microtemperature Signals of the Earth’s Crust. Papierflieger, Clausthal-Zellerfeld, Germany. 138-141 (1999)

52. L. Chen, et al., in The selected papers of earthquake prediction in China, edited by L. Li and B. Wu. (Seismological Press, State seismological Bureau, Beijing, China, 1996), pp. 242-254

53. V.M. Choubey, Kumar N., and Arora B.R., Sci. Tot. Environ. 407, 5877-5883 (2009)

54. Y. Chung, Pure Appl. Geophys. 122, 294-308. (1984)

55. L.L. Chyi, et al., Western Pacific Earth Sciences. 1, 227-246 (2001)

56. L.L. Chyi, et al., Terr. Atmos. Ocean Sci. 16, 763-774 (2005)

57. L. Claesson, et al., Geology (Boulder). 32, 641-644 (2004)

58. $\quad$ R.G.M. Crockett, et al., Sci. Tot. Environ. 364, 138-148 (2006)

59. $\quad$ N.K. Das, et al., Curr. Sci. 89, 1399-1404 (2005)

60. N.K. Das, et al., Radiat. Meas. 41, 634-637 (2006)

61. P. Einarsson, et al., Pure Appl. Geophys. 165, 63-74 (2008)

62. C.C. Fu, et al., Radiat. Meas. 43, S348-S352 (2008)

63. D. Ghosh, et al., Radiat. Meas. 42, 466-471 (2007)

64. D. Ghosh, et al., Nat. Hazards. 58, 877-889 (2011)

65. G. Giulinani, edited by W.I.P. Organization. (2004), pp. 15

66. E. Hauksson and Goddard J.G., J. Geophys. Res. 86, 7037-7054 (1981)

67. J. Heinicke and Koch U., Zeitschrift geologischer Wissenschaften. 21, 101-104 (1993)

68. J. Heinicke and Koch U., Pure Appl. Geophys. 157, 1621-1641 (2000)

69. J. Heinicke, Koch U., and Krbetschek M., Isotopenpraxis. 28, 337-348 (1993)

70. J. Heinicke, Koch U., and Martinelli G., Geophys. Res. Lett. 22, $771-774$ (1995)

71. $\quad$ B.F. Humanante, et al., Pure Appl. Geophys. 132, 505-20 (1990)

72. G. Igarashi and Wakita H., Tectonophysics. 180, 237-254 (1990)

73. G. Igarashi, et al., Science. 269, 60-61 (1995)

74. S. İnan, et al., J. Geophys. Res. 113, B03401 (2008)

75. $\quad$ S. Inan, et al., Geochem. J. 45, e11-e16 (2012)

76. T. Ito, et al., Geophys. Res. Lett. 26, 2009-2012 (1999)

77. S. Jónsson and Einarsson P., Seismology in Europe. 247-252 (1996)

78. I. Kawabe, Pure Appl. Geophys. 122, 194-214. (1984)

79. Y. Kawada, et al., Nonlinear Process. Geophys. 14, 123-130 (2007)

80. Y. Yasuoka, et al., Appl. Geochem. 21, 1064-1072 (2006)

81. Y. Yasuoka, et al., Appl. Geochem. 27, 825-830 (2012)

82. C.-Y. King, J. Geophys. Res. 85, 3065-78 (1980)

83. $\quad$ C.-Y. King, Pure Appl. Geophys. 122, 340-352. (1984)

84. C.Y. King, et al., Geophys. J. Int. 143, 469-477 (2000)

85. I.G. Kissin, et al., Izvestiya Academy of Sciences USSR, Physics of the Solid Earth. 19, $482-91$ (1983)

86. N. Koizumi, Yoshioka R., and Kishimoto Y., Geophys. Res. Lett. 12, 510-13 (1985)

87. $\quad$ N. Koizumi, et al., Geophys. Res. Lett. 31, L10606 (2004)

88. N. Koizumi, et al., Geophys. Res. Lett. 26, 3509-3513 (1999)

89. $\quad$ A. Kumar, et al., Appl. Radiat. Isot. 67, 1904-1911 (2009)

90. M.C.T. Kuo, et al., Ground Water. 44, 642-647 (2006)

91. T. Kuo, et al., J. Environ. Radioact. 88, 101-106 (2006)

92. T. Kuo, et al., Radiat. Meas. 44, 295-299 (2009)

93. T. Kuo, et al., Nat. Hazards. 59, 861-869 (2011)

94. T. Kuo, et al., Radiat. Meas. 45, 1049-1054 (2010)

95. T. Kuo, et al., Nat. Hazards. 53, 219-228 (2010)

96. I. Laskar, et al., Geochem. J. 45, 439-446 (2012)

97. $\quad$ K.K. Liu, et al., Pure Appl. Geophys. 122, 231-244. (1984)

98. I. Miklavcic, et al., Appl. Radiat. Isot. 66, 1459-1466 (2008)

99. K. Mogi, Mochizuki H., and Kurokawa Y., Tectonophysics. 159, 95-108 (1989)

100. H. Montazeri, Abbasnejad A., and Negarestani A., Geochem. J. 45, 463-472 (2011)

101. S. Nishizawa, et al., Appl. Geochem. 13, 89-94 (1998)

102. C. Papastefanou, Radiat. Meas. 45, 943-951 (2010)

103. N.M. Pérez, et al., Geochem. J. 42, 75-83 (2008)

104. J. Planinic, Radolic V., and Vukovic B., Nuclear Instruments \& Methods in Physics Research Section aAccelerators Spectrometers Detectors and Associated Equipment. 530, 568-574 (2004)

105. F. Poitrasson, et al., Earth Planet. Sci. Lett. 169, 269-276 (1999) 
106. R.C. Ramola, et al., Nucl. Geophys. 4, 275-287 (1990)

107. D.V. Reddy, et al., Radiat. Meas. 45, 935-942 (2010)

108. D.V. Reddy and Nagabhushanam P., Appl. Geochem. 26, 731-737 (2011)

109. G.M. Reimer, Pure Appl. Geophys. 122, 369-375. (1984)

110. G.M. Reimer, Nature. 347, 342-342 (1990)

111. P. Richon, et al., Geophys. Res. Lett. 30 (2003)

112. V.P. Rudakov, Geochem. Int. 41, 194-196 (2003)

113. H. Satake and et al., Pure Appl. Geophys. 122, 185-193. (1984)

114. N. Segovia, et al., Nat. Hazards. 1, 319-329 (1989)

115. M.H. Shapiro, et al., J. Geophys. Res. 85, 3058-3064 (1980)

116. V.M. Hamza, Phys. Earth Planet. Inter. 126, 163-177 (2001)

117. H. Shi and Cai Z., J. Geophys. Res. 91, 12282-12290 (1986)

118. M. Singh, et al., Nuclear Tracks and Radiation Measurements. 19, 1-4 (1991)

119. M. Singh, et al., Radiat. Meas. 30, 465-469 (1999)

120. S. Singh, et al., Terr. Atmos. Ocean Sci. 21, 685-695 (2010)

121. S.R. Steele, Geophys. Res. Lett. 8, 465-468 (1981)

122. G. Steinitz, Begin Z.e.B., and Gazit Y.N., Geology (Boulder). 31, 505-508 (2003)

123. R. Sugisaki, Nature. 275, 209-211 (1978)

124. R. Sugisaki and Sugiura T., J. Geophys. Res. 91, 12296-12304 (1986)

125. C. Tang, Chin. Geophys. 1, 400-424 (1978)

126. T. Teng and Sun L.F., J. Geophys. Res. 91, 12305-12313 (1986)

127. J.P. Toutain, et al., Earth Planet. Sci. Lett. 149, 113-119 (1997)

128. U. Tsunogai and Wakita H., Science. 269, 61-63 (1995)

129. V.I. Utkin, et al., Izvestiya Physics of the Solid Earth. 42, 775-784 (2006)

130. H.S. Virk, Nucl. Geophys. 9, 141-146 (1995)

131. H.S. Virk and Singh B., Tectonophysics. 227, 215-224 (1993)

132. H.S. Virk and Singh B., Geophys. Res. Lett. 21, 737-740 (1994)

133. H.S. Virk and Walia V., Radiat. Meas. 34, 379-384 (2001)

134. H.S. Virk, Walia V., and Kumar N., J. Geodyn. 31, 201-210 (2001)

135. H. Wakita, in A Collection of Papers of the International Symposium on Continental Seismicity and Earthquake Prediction. (Seismological Press, Beijing, 1984), pp. 494-500

136. H. Wakita, Igarashi G., and Notsu K., Geophys. Res. Lett. 18, 629-632 (1991)

137. V. Walia, et al., Terr. Atmos. Ocean Sci. 16, 775-804 (2005)

138. C.Y. Wang, Chin. Geophys. 1, 157-172 (1978)

139. K. Wattananikorn, Kanaree M., and Wiboolsake S., Radiat. Meas. 29, 593-598 (1998)

140. W. Zhang and Wang C., in Collected Papers of the Methods of Earthquake Prediction and estimation of strong seismic risks, edited by C. Zhangli. (Seismological Press, 1990), pp. 121-136

141. B. Zmazek, et al., Appl. Radiat. Isot. 57, 919-930 (2002)

142. B. Zmazek, et al., Appl. Geochem. 20, 1106-1119 (2005)

143. P.P. Firstov, Filippov Y.A., and Mandrikova O.V., Dokl. Earth Sci. 389, 462-465 (2003)

144. A. Skelton, et al., Nat. Geosci. 7, 752-756 (2014)

145. H. Woith, et al., Geochem. J. 45, 473-482 (2011)

146. M. Trique, et al., Nature. 399, 137-141 (1999)

147. $\quad$ S.M. Barbosa, et al., Geophys. Res. Lett. 34 (2007)

148. G. Steinitz, Piatibratova O., and Barbosa S.M., J. Geophys. Res. 112, 19 (2007)

149. I.P. Dobrovolsky, Zubkov S.I., and Miachkin V.I., Pure Appl. Geophys. 117, 1025-1044 (1979)

150. A. Gregorič, et al., in Earthquake Research and Analysis - Statistical Studies, Observations and Planning, edited by S. D'Amico. (InTech, Rijeka, Croatia, 2012), pp. 179-196

151. R.F. Holub and Brady B.T., J. Geophys. Res. 86, 1776-1784 (1981)

152. $\quad$ G.M. Varshal, et al., Pure Appl. Geophys. 122, 463-477 (1984)

153. S. Mollo, et al., Geophys. Res. Lett. 38, L14304 (2011)

154. A. Nicolas, et al., Geophys. Res. Lett. 41, 5436-5443 (2014)

155. B. Mavashev, in The Israel Mineral Science and Engineering Association, 13th annual meeting. (Jerusalem, Israel, 1996)

156. V.L. Barsukov, et al., Pure Appl. Geophys. 122, 157-163. (1984)

157. C.-Y. King, et al., Geophys. Res. Lett. 8, 425-8 (1981)

158. J.R. O'Neil and King C.-Y., Geophys. Res. Lett. 8, 429-432 (1981)

159. H.-J. Kümpel, Tectonophysics. 211, 317-336 (1992)

160. J.P. Toutain, et al., Pure Appl. Geophys. 163, 723-744 (2006)

161. H. Woith, et al., Chem. Geol. 339, 177-186 (2013)

162. L.L. Chyi, et al., Geofluids. 10, 556-563 (2010)

163. G. Etiope and Martinelli G., Phys. Earth Planet. Inter. 129, 185-204 (2002)

164. F. Perrier, et al., Earth Planet. Sci. Lett. 278, 198-207 (2009)

165. A. Brown, AAPG Bull. 84, 1775-1789 (2000)

166. M.H. Shapiro, et al., Pure Appl. Geophys. 122, 309-326. (1984)

167. B. Zmazek, et al., Appl. Radiat. Isot. 58, 697-706 (2003)

168. J. Zschau, et al., Eos, Transactions, American Geophysical Union. 63, 1272 (1982) 
169. H. Woith, PhD. Christian-Albrechts-University Kiel, 1996

170. E. Greber, PhD. ETH, 1992

171. R. Wang, et al., Geophys. J. Int. 157, 717-726 (2004)

172. H. Woith, et al., Hydrogeol. J. 11, 113-121 (2003)

173. F.H. Weinlich, et al., Tectonophysics. 421, 89-110 (2006)

174. K. Bräuer, et al., Journal of Geophysical Research, B, Solid Earth and Planets. 108, 2070 (2003)

175. H. Brandes, PhD. Christian-Albrechts-University Kiel, 1905

176. J.E. Elkhoury, Brodsky E.E., and Agnew D.C., Nature. 441, 1135-1138 (2006)

177. R. Yan, Woith H., and Wang R., Geophys. J. Int. 199, 533-548 (2014)

178. R.H. Sibson, in Geofluids: Origin, Migration and Evolution of Fluids in Sedimentary Basins, edited by J. Parnell. (The Geological Society, London, 1994), pp. 69-84

179. R.H. Sibson, Tectonophysics. 473, 404-416 (2009)

180. R.H. Sibson, J. Struct. Geol. 18, 1031-1042 (1996)

181. N. Matsumoto and Koizumi N., Nat. Hazards. 69, 1247-1260 (2013)

182. $\quad$ S. Itaba, et al., Pure Appl. Geophys. 167, 1105-1114 (2010)

183. H.-J. Kümpel, Tectonophysics. 193, 377-383 (1991)

184. N. Matsumoto, Geophys. Res. Lett. 19, 1193-1196 (1992)

185. Y. Okada, Bull. Seismol. Soc. Am. 82, 1018-1040 (1992)

186. J. Hartmann and Levy J.K., Hydrogeol. J. 14, 1307-1318 (2006)

187. P. Bernard, Tectonophysics. 338, 225-232 (2001)

188. G. Martinelli, Physics and Chemistry of the Earth Part a-Solid Earth and Geodesy. 25, 337-341 (2000)

189. F. Italiano, Martinelli G., and Plescia P., Pure Appl. Geophys. 165, 75-94 (2008)

190. G. Etiope and Lombardi S., Environ. Geol. 27, 226-232 (1996)

191. R. Emmermann and Lauterjung J., J. Geophys. Res. 102, 18179-18201 (1997)

192. F.L. Niu, et al., Nature. 454, 204-U44 (2008)

193. M. Zoback, Hickman S., and Ellsworth W., Scientific Drilling. 14-28 (2011) 